\title{
Aspiration of Tooth in A Tracheotomised Patient- A Rarecase Report And Review Of Literature.
}

\author{
Dr. PrajwalitPrakashKende ${ }^{1}$, Dr. JayantLandge ${ }^{2}$, Dr. Natarajan $C^{3}$, \\ Dr. Navneet Sharma ${ }^{4}$ \\ ${ }^{I}$ M.D.S. (Maxillofacial \& Oral Surgery), Associate Professor\& HOD, Department of Maxillofacial \& Oral \\ Surgery, Government Dental College \& Hospital, Mumbai. Mobile- 9324715824 \\ ${ }^{2}$ M.D.S. (Maxillofacial \& Oral Surgery), Assistant Professor, Department of Maxillofacial \& Oral Surgery, \\ Government Dental College \& Hospital, Mumbai. Mobile- 9833644688 \\ ${ }^{3}$ M.D.S(Maxillofacial \& Oral Surgery), Assistant Professor, Department of Maxillofacial \& Oral Surgery, \\ Government Dental College \& Hospital, Mumbai. Mobile- 9004168964 \\ ${ }^{4}$ M.D.S. (Maxillofacial \& Oral Surgery), Assistant Professor, Department of Maxillofacial \& Oral Surgery, \\ Government Dental College \& Hospital, Mumbai. Mobile- 9833685485
}

\begin{abstract}
Aspiration of tooth by conscious patient is not a common occurrence in exodontia. Most cases of aspiration are secondary to maxillofacial trauma and during intubation for general anesthesia. There are isolated case reports of aspiration oftooth during extraction in pediatric age group. Here we present a case report of aspiration of tooth by a conscious tracheotomised adult patient and the difficulties encountered in retrieving the tooth along with the review of literature. Aspiration in this case can be attributed to the diminished gag and cough reflexes caused by the tracheotomy of the patient. A step by step protocol has been devised to manage such situations.
\end{abstract}

Keywords:Aspiration, maxillofacial trauma, intubation, tracheotomy, gag reflex, cough reflex

\section{Introduction}

Entry of solid particles or fluid into the airway is termed as aspiration. Aspiration is almost always accidental and cannot be done voluntarily. Ingestion is entry of solid particles or fluid into stomach through the esophagus. It can be voluntary or involuntary. The most common causes of aspiration include maxillofacial trauma, altered consciousness, and intubation. Aspiration can lead to atelectasis, pneumonia and respiratory failure. Aspiration of tooth is a serious complication in exodontia requiring immediate attention to avoid potentially fatal complications. It was Hedbolm in 1932, who reported 32 cases of foreign body aspiration of dental origin with broncho-pulmonary complications [1]. There are not much reported cases of tooth aspiration in conscious adult patients in the literature. The peculiarity of this case report is that since the patient was tracheotomised all his gag reflexes and cough reflexes were diminished that attributed to aspiration.

\section{Case report}

A sixty year old male patient reported to the department of oral and maxillofacial surgery for extraction of 48 (Figure 1). Patient was a known case of oral squamous cell carcinoma and was operated three months before with righthemimandibulectomy and reconstruction with pectoralis major myocutaneous flap. Patient was referred from the department of plastic surgery for extraction of 48 as it was causing traumatic ulcerations over the rightbuccal mucosa. Patient was tracheotomised and had mildly restricted mouth opening. Patient gave no history of any other medical ailments. After taking informed consent, under strict aseptic protocol, a rightpterygomandibular nerve block and a right long buccal nerve block was given with $2 \%$ lignocaine with 1 : 80,000 adrenaline. While extraction of tooth was carried out, the tooth slipped out from the forceps and was lost in the oral cavity. Immediate search was made in the oral cavity upto the oro pharyngeal region, but tooth was not found. Search was extended to the spittoon and the floor but all in vain. Presuming aspiration of tooth, patient's vitals were assessed and was confirmed stable. Patient was shifted to the general hospital casualty immediately. His postero anterior (PA) and lateral neck radiographs were made which revealed the tooth above the tracheotomy tube (Figure 2). Patient was then taken in operation theatre on an emergency basis and with the help of the anesthetist under aseptic protocol, a laryngoscopy was done. As the tooth was not seen it was decided to go for flexible fiber optic bronchoscopy. When the tooth was identified patient had bouts of cough and the tooth was lost again. Patient was then mildly sedated and search was made in the airway. As the tooth could not be found search was extended to the upper part of the esophagus. Tooth was not found and as the bronchoscope was being retrieved for a repeat radiography, accidentally tooth was seen in the smugglers fossa aka piriform fossa after which it was removed with the flexible foreign body claw(Figure $3 \& 4$ ). Patient was 
kept under observation for two hours and then discharged. Patient was advised amoxicillin 500mg t.i.d and diclofenac 50mg t.i.d for five days but the patient didn't turn for the follow-up.

\section{Discussion}

Tooth aspiration is an uncommon occurrence with an overall incidence of $0.4 \%$ and is more uncommon in conscious adult patients compared to children [2]. Usually aspirated tooth are lodged in right bronchus because of its straighter course and in line with the trachea. Following aspiration, patients will have coughing and gaging with wheeze and stridor. But $3 \%$ of patients will not have any immediate symptoms [3].

Radiographic examinations include PA chest, Lateral chest, PA and lateral neck, with inspiratory and expiratory studies. Fluoroscopy can also be used to detect foreign bodies. Radiolucent foreign bodies cannot be detected through routine radiography in which case secondary effects of aspiration including emphysema, mediastinal shift, atelectasis, and pneumonia will provide vital clues for diagnosis along with a careful history. A rigid or a flexible bronchoscope can be used to remove the tooth. Earlier, rigid bronchoscope was most commonly used for retrieval of foreign body but rigid bronchoscopes are contraindicated in patients with suspected neck injuries in which case a flexible fiber optic bronchoscope can be used as it doesn't require any neck extension. Both rigid and flexible bronchoscopes have a foreign body claw to hold the tooth and retrieve it [4]. Rare instances require open surgical procedure via lateral thoracotomy [5].

In this case patient was an operated case of oral squamous cell carcinoma with restricted mouth opening and tracheotomy tube in place. As the patient had traumatic ulceration due to right lower third molar he was advised extraction by the plastic surgeons. Tracheotomised patients have diminished gag reflex, 20\% of them may have no gag reflex at all [6]. Further as vocal cords are bypassed, there is no laryngeal blast for effective coughing [7]. Most importantly their aphonia presents a greater barrier for patient care. All these factors together contributed for aspiration of tooth in our patient [8].

As the patient coughed the tooth was displaced into the smugglers fossa aka piriform fossa which is present on either side of the laryngeal orifice. Its medial wall is formed by aryepiglottic fold and lateral wall is formed by thyroid cartilage and thyrohyoid membrane. Deep to the mucosal lining of the fossa are the recurrent laryngeal and the internal laryngeal nerves. Any inadvertent breach in this lining can damage these nerves. It is common for foreign bodies to get lodged in this fossa in infants which can be removed non-surgically.

Aspirated tooth is usually slippery and difficult to grasp with foreign body claw of the bronchoscope. Further after a period of time granulation tissue forms around the tooth making it difficult to identify in the radiographs and results in bleeding which obscures the field of vision while retrieving, necessitating surgical removal.

Hedbolm in 1920 reported 32 cases of foreign body aspiration of dental origin in patients with broncopulmonary complication [1]. It was Jackson and Jackson in 1934 who described three phases of aspiration. Acute phase which starts immediately after aspiration and lasts for few minutes is characterized by paroxysmal episodes of coughing. This is followed by quiescent phase where the patient is asymptomatic, which may last for about a week. In this phase there is formation of a check valve allowing inflow of air across the foreign body but preventing outflow of air. This results in expiratory ronchi, obstructive emphysema, mediastinal shift, pulmonary hyperinflation. Finally, after a week's time patient enters the complication phase. Here in this phase, the check valve becomes a stop valve and results in atelectasis and bronchopneumonia [9]. In 1997,Ochmanski et al reported a case of foreign body aspiration which was misdiagnosed as bronchial neoplasm [10]. In 2004 Bergthordotir et al reported a case of endo bronchial actinomycosis not responding to antibiotics after tooth aspiration [11].Summarized data of seven published articles are presented in table 1.

As the famous adage goes 'prevention is better than cure', all possible efforts should be made to prevent aspiration or ingestion of tooth. Where ever possible throat screens should be used and avoid reclining the patient far back.

Though aspiration is not a common occurrence it is essential to have a distilled protocol to be followed during such situations. We in our institute follow this five step protocol.

Step: 1- Check for the tooth thoroughly in the oral cavity, if not found check around the patient including the spittoon.

Step: 2- If tooth is not found assume it is aspirated and put the patient in reverse trendlenberg position and encourage coughing. If tooth is not coughed out, perform Heimlich maneuver.

Step: 3 -Check the vitals of the patient, in case of any drop in oxygen saturation provide $100 \%$ oxygen.

Step: 4 -Shift the patient to emergency medical unit and perform diagnostic radiography.

Step: 5 -If patient's general condition is stable take the patient in emergency operation theatre and with the help of anesthetist perform a flexible fiber optic bronchoscopy and retrieve the tooth with or without sedation and follow up for a month. 


\section{Conclusion}

Though uncommon, aspiration of tooth is potentially fatal and requires early diagnosis and prompt management. Every possible care should be taken to prevent any such aspiration and a strict institutional protocol should be followed in case of any such adverse event.

\section{Acknowledgements}

Source of support: Nil, Conflict of interest: None Declared

\section{References}

[1]. Hedblom CA.: Foreign bodies of dental origininbronchopulmonary complication. Ann Surg 1920; 71:568-80.

[2]. Baharloo F, Veyckemans F, Francis C, Biettlot MP, Rodenstein DO. Tracheobronchial foreign bodies: presentation and management in children and adults. Chest 1999; 115:1357-62.

[3]. Steen KH, Zimmerman T, Tracheobronchial aspiration of foreign bodies in children. A study of 94 cases. Laryngscope 1990; 100: 525-30.

[4]. Ludemann JP, Hughes CA, Hollinger LD: Management of foreign bodies of the airway. In Shields TW, Locicero J, Ponn RB, editors: General thoracic surgery $5^{\text {th }}$ edi Philadelphia: Lippencott Williams and Wilkens; 2000 p853-61.

[5]. Ulku R, Baskan Z, Yavuz I: Open surgical approach for a tooth aspirated during dental extraction: A case report. Aus Dent J 2005; $50:(1): 49-50$

[6]. Heffner JE. The technique of weaning from tracheostomy: criteria for weaning; practical measures to prevent failure. J critIlln 1995; 10(10):729-733.

[7]. Kent L Christopher. Tracheostomy Decannulation. Respir Care 2005; 50(4):538-41.

[8]. Rosemary Pudner:Nursing the surgical patient. $2^{\text {nd }}$ edi 207.

[9]. Jackson C, Jackson CL: Bronchoscopy, esophagoscopy and gastroscopy. A manual of peroral endoscopy and laryngeal surger,y $3^{\text {rd }}$ edi Philadelphia W.B. Saunders company 1934.

[10]. Ochmanski W, Krawczyk K.: Foreign body imitating bronchial neoplasm. Przegladleic 1997; 54(1)0-72 (polish).

[11]. Bergthorsdottir R, Benediktsdottirke, thorstein SB, baldursson O.:Endobronchialactinomycosis secondary to a tooth aspiration. Scan J Infect Dis 2004; 36(5):384-6.

[12]. Karen K Tiwana et al: Aspiration and ingestion in dental practice. A 10 year institutional review. JADA Sep 2004 vol135.

[13]. RobrertSteelman et al: Aspiration of tooth in a patient with a tracheostomy, special are in dentistry 1997 vol17 no 3.

[14]. Juan C. Ospina et al: Aspiration of an extracted molar: Case report. J Can Dent Assoc 2005: 71(8): 581-3.

[15]. Mao Zhang et al: Delayed diagnosis of tooth aspiration in three multiple trauma patients with mechanical ventilation. Crit Care. $2011 ; 15(3): 424$.

[16]. S Kant, S Verma, VMahajan.: Spontaneous expulsion of aspirated teeth in left lung following maxillofacial trauma: Case Report. The Internet Journal of Pulmonary Medicine. 2006 Volume 8 Number 2.

[17]. Niraj Kumar et al: Management of aspirated tooth in an adult head injury patient: Report of two cases. Saudi Journal of Anesthesia Vol. 8, Issue 2, April-June 2014.

Table 1

Summarized data of seven published articles

\begin{tabular}{|c|c|c|c|c|c|c|}
\hline Sr.No & Study & Study Design & $\begin{array}{l}\text { Number of } \\
\text { Documented } \\
\text { cases }\end{array}$ & $\begin{array}{l}\text { Cause of } \\
\text { aspiration }\end{array}$ & Treatment done & Complications \\
\hline 1. & Karen et al.[12] & $\begin{array}{l}\text { Retrospective } \\
\text { study } \\
\text { (10 years) }\end{array}$ & $\begin{array}{l}36 \\
\text { (ingestion }+ \\
\text { aspiration) }\end{array}$ & $\begin{array}{l}\text { Not } \\
\text { discussed }\end{array}$ & Not discussed & Not discussed \\
\hline 2. & $\begin{array}{l}\text { Robert Steelman } \\
\text { et al.[13] }\end{array}$ & Case report & 1 & $\begin{array}{l}\text { Exfoliation } \\
\text { of primary } \\
\text { teeth in } \\
\text { cerebral } \\
\text { palsy } \\
\text { patient }\end{array}$ & Bronchoscopy & Nil \\
\hline 3. & $\begin{array}{l}\text { Juan C. Ospina } \\
\text { et al.[14] }\end{array}$ & Case report & 1 & $\begin{array}{l}\text { Dental } \\
\text { extraction }\end{array}$ & Rigid bronchoscopy & Nil \\
\hline 4. & R Ulku et al[5] & Case report & 1 & $\begin{array}{l}\text { Dental } \\
\text { extraction }\end{array}$ & Open bronchotomy & Nil \\
\hline 5. & Mao Zhang et al[15] & Case report & 3 & Trauma & $\begin{array}{l}2 \text { cases- failed attempt } \\
\text { in tooth retrieval by } \\
\text { bronchoscopy } \\
1 \text { case- successful } \\
\text { flexible fibreoptic } \\
\text { bronchoscopy tooth } \\
\text { retrieval }\end{array}$ & $\begin{array}{l}1 \text { patient died } \\
\text { of sepsis }\end{array}$ \\
\hline 6. & S Kant et al[16] & Case report & 1 & Trauma & $\begin{array}{l}\text { Spontaneous } \\
\text { expulsion of tooth }\end{array}$ & Nil \\
\hline 7. & Niraj Kumar et al[17] & Case report & 2 & Trauma & Rigid bronchoscopy & Nil \\
\hline
\end{tabular}


Figures

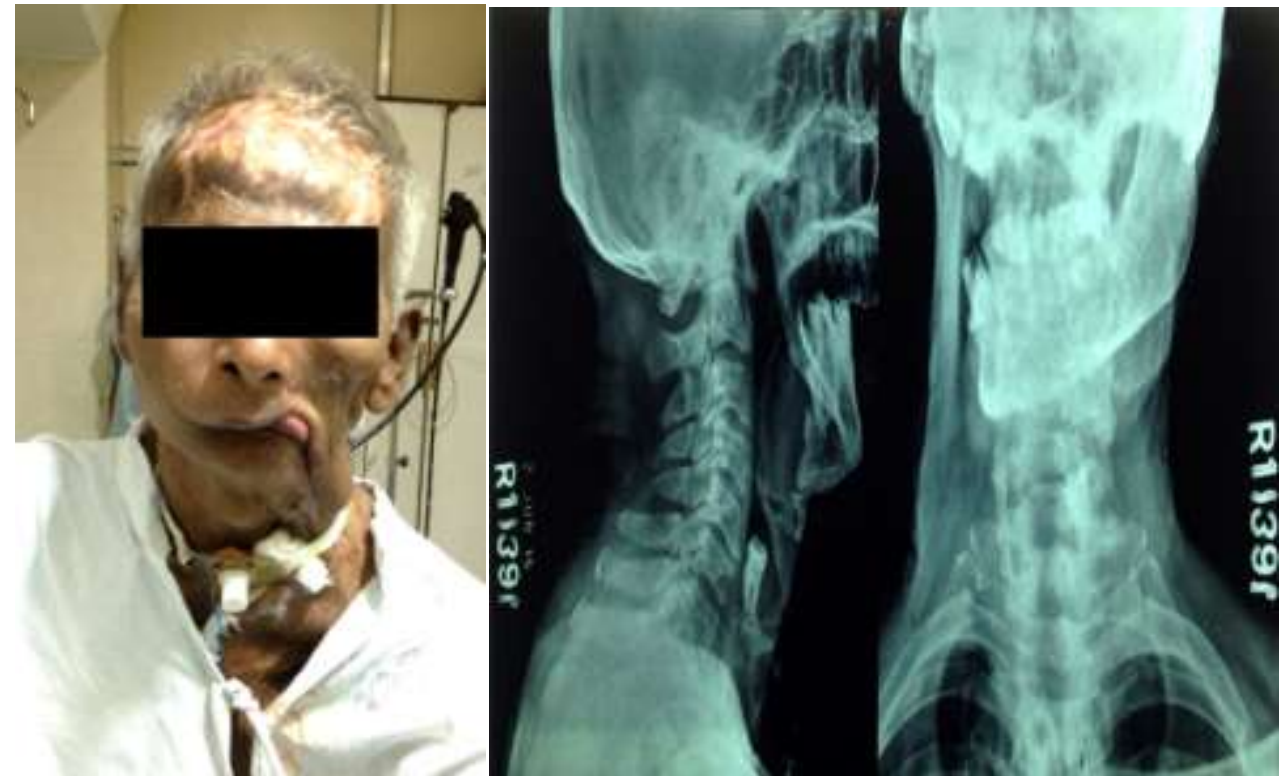

Fig 1 Preoperative frontal view

Fig 2 Radiographs after aspiration of tooth

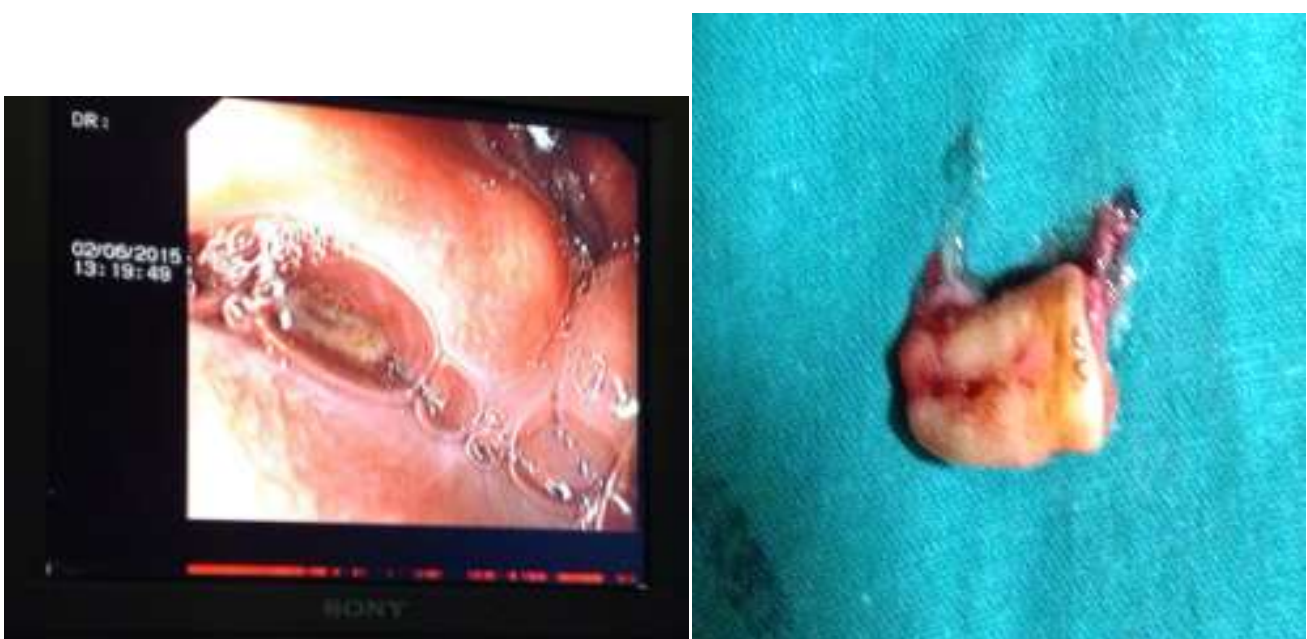

Fig 3 Tooth located in smugglers fossa Fig 4 Tooth retrievedduringflexible fiberoptic bronchoscopy 